\title{
Interpretation of bone densitometry and definition of osteoporosis in children and adolescents
}

\author{
Małgorzata Morawiecka-Pietrzak ${ }^{1,2}$, Katarzyna Ziora' ${ }^{1}$ Zofia Ostrowska² \\ 'Department of Pediatrics, School of Medicine with the Division of Dentistry in Zabrze, Medical University of Silesia, \\ Zabrze, Poland \\ ${ }^{2}$ Department of Medical and Molecular Biology, School of Medicine with the Division of Dentistry in Zabrze, Medical \\ University of Silesia, Zabrze, Poland
}

\section{ABSTRACT}

Paediatric age is a crucial time for bone mass accrual. Every deterioration of bone status in this period of life can affect the condition of the skeleton in the future. The awareness of primary and secondary disorders affecting bone health is vital for the identification of children at risk of developing osteoporosis. Among currently available methods of measuring bone mineral density in children, dual energy X-ray absorptiometry (DXA) remains the method of choice. However, the interpretation of a paediatric DXA report is complicated, which can lead to a misdiagnosis. Unlike in adults, the result is given in the $Z$-score; the $T$-score should not be taken into account. The preferred sites of measurement are the total body less head, and the lumbar spine. The current recommendations for bone mineral density assessment are provided by the International Society for Densitometry.

\section{KEY WORDS:}

children, osteoporosis, DXA.

\section{INTRODUCTION}

Osteoporosis and bone fragility in children, resulting in an increased risk of fractures, can reduce the quality of life significantly and lead to significant morbidity. The aim of clinical practice is to prevent fractures in at-risk children before such fractures occur, and to decrease the probability of their recurrence [1]. There is a need to increase awareness among paediatricians so they can identify patients at risk of developing osteoporosis, because early detection and intervention are essential. The method of choice in measuring the bone mass since the 1980s has been dual-energy X-ray absorptiometry (DXA). Because of problems in the interpretation of DXA results, the International Society for Densitometry provides Official Po- sitions for the use of this diagnostic tool in the paediatric population. The recommendations were re-evaluated at a Position Development Conference (PDC) in 2013 in Baltimore.

\section{OSTEOPOROSIS}

Osteoporosis is defined as a low bone mass and microarchitectural deterioration of the bone structure, resulting in an increased bone fragility and fracture risk $[2,3]$. Peak bone mass is achieved in the third decade of a person's life; hence, the foundations of adult bone health are built during childhood and the teenage years [4-6]. This period of bone mass accrual is crucial because people with a high peak bone mass are at lower risk of

\section{ADDRESS FOR CORRESPONDENCE:}

Małgorzata Morawiecka-Pietrzak, Department of Pediatrics, School of Medicine with the Division of Dentistry in Zabrze, 13/15 3 Maja St., 41-800 Zabrze, Poland, ORCID: 0000-0002-3449-5684,

e-mail: morawieckam@gmail.com 
osteoporotic fracture later in life [7]. One of the most significant factors influencing bone development is genetics - as much as $60-80 \%$ of differences in bone mass among individuals are determined by genetic factors $[1,6,8]$. There are also studies reporting that white Caucasian origin is a risk factor of fracture as opposed to children of black African origin. According to Wren et al., healthy children of European ancestry exhibit a fracture risk twice as high as do healthy subjects of another origin [9]. However, genetics and ethnicity are invariable factors. Among lifestyle factors influencing the bone health, nutritional status and weight-bearing exercises are vital in the prevention of osteoporosis. Adequate calcium intake and vitamin D supplementation have been proven to enhance the peak bone mass in healthy children; most paediatric subjects do not consume the recommended dose of calcium [10]. The effect of childhood overweight/ obesity on bone health remains unclear. There are some reports suggesting that an increased body mass in children and teenagers has a positive effect on the bone mass and density. It seems that differences in the bone mineral density (BMD) in overweight and obese paediatric subjects depend on the fat mass (FM) and the lean mass (LM) - a protective effect of LM on the bone health is well known, while individuals with the same body mass index (BMI) may have different FM and LM proportions. The effect of FM on the bone health is controversial; it differs depending on the individuals' age and sex, and the measured site $[7,11]$. On the other hand, some literature emphasises that excessive body weight may be a risk factor for impaired bone mineralisation and structure [12]. This may be due to insufficient calcium intake, sedentary lifestyle, vitamin D deficiency, and insulin resistance [11]. In turn, underweight increases the risk of fractures [13]. One of the factors influencing BMD in underweighted children is low LM [11]. Physical activity has an anabolic effect on the growing skeleton, and it has been proven that it increases the bone mass in healthy children and teenagers $[1,14]$. According to the mechanostat theory, mechanical factors, such as muscle force, regulate bone mass and shape. Immobilisation and lack of physical activity affect the integrity of the muscle bone unit [2]. This is consistent with the positive effect of LM on the bone mass - bigger muscles exert higher tensile forces on the attaching bones [11]. However, it has been proven that the benefits of physical activity appear maximal under the conditions of an adequate calcium intake [15].

Every other factor that affects bone mass accrual in childhood and adolescence can contribute to a lower bone mass in adulthood. In young growing patients a lot of diseases and pharmacological agents can result in bone loss, a suboptimal increase in bone mass, or a combination of both [4]. Survivors of paediatric and adolescent cancers, patients after bone marrow transplantation, and those who have been treated with glucocorticosteroids (GC) and methotrexate, and those suffering from other states that disturb the bone mass accrual face an increased fracture risk. In some paediatric glucocorticoid-treated disease groups, the prevalence of vertebral fractures is as high as $50 \%$ [16]. At the same time, in children with motor impairment not treated with GC, vertebral fractures occur in $25 \%$ of patients [17].

\section{CLINICAL SYMPTOMS OF OSTEOPOROSIS IN CHILDREN AND ADOLESCENTS}

A typical sign of osteoporosis is a history of recurrent low-energy fractures. Vertebral fractures can present with moderate to severe backache (in at-risk children pain in the back is a good indicator of vertebral fracture), pulmonary restriction, or gastrointestinal symptoms, but they are often asymptomatic $[2,3,17]$. In contrast to extremity bones, vertebrae contain a higher amount of trabecular bone, which is more metabolically active. Hence, this part of the skeleton is more exposed to the effect of osteotoxic agents, e.g. GC. The most vulnerable vertebrae, with the most fractures in this location, are in the upper thoracic (T6/7) and lumbar spine (L1/2) [16].

\section{ASSESSMENT OF THE BONE MINERAL DENSITY AND BONE MINERAL CONTENT}

Among children and adolescents, the recommended technology for clinical measurement of bone mineral density (BMD) and bone mineral content (BMC) is DXA. It is a radiological method that detects the attenuation of two photon beams of different energies as they pass through the soft tissue and bone. DXA remains a method of choice because of its availability, low ionising radiation exposure, precision, scan speed, and robust normative paediatric databases $[3,6,8,18]$. In most subjects the posteroanterior lumbar spine (L1-L4) and the total body less head (TBLH) are the skeletal sites of choice [19]. These sites reflect the trabecular and cortical bone, respectively, and it is believed that they provide an insight into the overall bone status $[4,18,20]$. Exclusion of the head is recommended because the skull constitutes a relatively large portion of the total body bone mass and its mineralisation is little influenced by activity, nutritional, or lifestyle factors. Moreover, skull fractures do not represent true osteoporotic fractures. Inclusion of the head potentially masks gains or losses of BMD at other skeletal sites $[3,6,8,20]$. The wholebody scan allows also the evaluation of soft tissues - the DXA scanner generates the BMD and the body composition measurement simultaneously. These reports may be helpful, especially in children with chronic illnesses, in particular considering that several studies have proven that there is a high correlation between muscle mass and bone mass in children, consistent with the functional bone-muscle unit theory [4]. Unlike in adults, the hip is not a preferred measurement site in growing children 
due to the differences in the skeletal development. If there is no possibility of scans of the recommended sites (e.g. because of joint contractures, immobilisation, metal implants), an alternative site is the lateral distal femur (LDF) $[4,18]$. According to the study by Zemel et al., the LDF measurement is significantly associated with other clinical bone density assessment modes [21]. Moreover, this location may be helpful in immobilised children, because bone fragility is highest in the lower extremities [1]. Also, the distal forearm is considered to be a potential site of examination in obese children (who exceed the scanner weight limit). However, it has to be kept in mind that this site has the poorest precision of all the measurement sites $[4,20]$. The ISCD Positions also emphasise that the measurement should not be performed if a safe position cannot be assured (in the event of e.g. contractures, immobilisation) [22].

In addition to assessing the bone mineral density, DXA can also be a tool for detecting moderate and severe vertebral fractures. Although a current gold standard to detect vertebral fractures is a radiograph, the vertebral fracture assessment by DXA (VFA) has many advantages compared to the conventional X-ray scan: the DXA scanner is able to acquire the whole spine (in both the posteroanterior and lateral projections) in a single projection, which allows minimisation of the radiation dose for children, which is $10-100$ times lower than the radiation during a conventional radiograph. Additionally, VFA is better than an X-ray scan in identifying fractures in the thoracic region, which is the most common region of vertebral crushes. Moreover, VFA can be obtained during the DXA assessment, which allows additional ionisation to be avoided. The limitation of VFA is a lower image resolution compared to X-ray $[4,17]$.

\section{SAFETY OF DXA AND IONISING RADIATION}

DXA is a safe method, and there is no known health risk associated with the ionising radiation during the examination. The estimated exposure is 5-6 $\mathrm{Sv}$, which only slightly exceeds the natural cosmic radiation [23].

\section{DEFINITION OF OSTEOPOROSIS AND INDICATIONS FOR ORDERING DXA IN CHILDREN AND ADOLESCENTS}

According to the official Paediatric Positions of ISCD, the diagnosis of osteoporosis should not be made on the basis of densitometry alone. The current guidelines put the weight of the diagnosis on the clinical evidence of bone fragility. Nowadays, osteoporosis in children and adolescents is defined as one or more vertebral compression fractures (loss of $>20 \%$ of height at any point) in the absence of a local disease or a high-energy trauma. In the presence of the history of a low-impact vertebral fracture, measuring BMD is not required as a diagnostic criterion, but adds to the overall assessment of the skeletal status [8]. If there is no history of vertebral crush fractures, osteoporosis is diagnosed when both are present: the BMD $Z$-score of -2.0 or lower, and a clinically significant fracture history, which has been defined as one or more of the following: 1) two or more long bone fractures by the age of 10 years; 2) three or more long bone fractures at any age up to 19 years $[8,18,19]$.

Densitometric assessment is ordered to identify patients at a higher risk of skeletal fragility fractures to implement the correct therapy and to monitor the patient's responses to the treatment. According to Clark et al., a low bone mass and decreased BMD are connected with an increased risk of fractures [24]. Despite that, a routine DXA is not recommended in healthy children; only if there is a clinically significant fracture history or a single low-impact vertebral compression fracture, history of recurrent fractures, back pain, spinal deformity, or loss of height, is densitometry indicated in otherwise healthy subjects. It should be emphasised that recurring finger and foot bone fractures do not qualify for osteoporosis diagnosis in children $[6,8,18]$.

ISCD Positions also include guidelines for densitometry in infants and children less than five years old. Although the relation between bone accretion in infancy and early childhood and bone health in older ages is unknown, it seems that poor bone mass accrual during growth has an impact on the lifelong bone strength. The bone mass of infants and young children may be affected by diverse pharmaceutical agents applied in some chronic conditions. Also, surviving children (e.g. after extreme prematurity, cancer, or congenital heart disease) may require control of their bone health. Densitometry in the very young aims to determine the fracture risk in order to identify the disease- or treatment-related effects [25]. The recommended measurement technique is DXA, and the preferred sites are the lumbar spine (for children aged 0-5 years) and the whole body (for subjects aged $\geq 3$ years). These scans are feasible, although it has to be kept in mind that every significant motion can cause an artefact, and scans are then uninterpretable. However, the lumbar spine scan and other regional scans are more likely to be movement-free because of the shorter scan time $(<30 \mathrm{~s})$, while the whole-body scan lasts about 2-3 min [25].

Another group of patients among whom DXA should be conducted are children with primary bone diseases or secondary disorders that increase the fracture risk. Primary osteoporosis occurs in most cases in an otherwise healthy child because of an intrinsic skeletal defect of genetic or idiopathic origin, typically with a family history. A secondary bone disease is a complication in the course of a chronic illness or its treatment [2]. In these subjects DXA is a useful part of the bone health assessment [22]. There are even specific recommendations to monitor the skeletal status in cystic fibrosis and cancer survivors $[10,26]$. States that may influence the bone 
TABLE 1. Primary bone diseases and secondary disorders associated with low bone mass and increased fracture risk

\begin{tabular}{|c|c|}
\hline $\begin{array}{l}\text { Primary bone } \\
\text { diseases }\end{array}$ & $\begin{array}{l}\text { - osteogenesis imperfecta } \\
\text { - juvenile idiopathic osteoporosis }\end{array}$ \\
\hline \multirow[t]{13}{*}{$\begin{array}{l}\text { Secondary } \\
\text { disorders }\end{array}$} & $\begin{array}{l}\text { Endocrine disorders: } \\
\text { - hypogonadism } \\
\text { - hyper- and hypothyroidism } \\
\text { - hypopituitarism } \\
\text { - ovarian insufficiency } \\
\text { - type } 1 \text { diabetes mellitus } \\
\text { - Cushing's syndrome }\end{array}$ \\
\hline & $\begin{array}{l}\text { Haematological and oncological diseases } \\
\text { - thalassaemia } \\
\text { - sickle cell disease } \\
\text { - leukaemia, lymphoma }\end{array}$ \\
\hline & Inflammatory bowel disease \\
\hline & Rheumatologic disorders \\
\hline & Renal disease \\
\hline & Celiac disease \\
\hline & Neuromusculoskeletal disorders \\
\hline & Cystic fibrosis \\
\hline & Transplantation (excluding kidney) \\
\hline & Malnutrition \\
\hline & Chronic immobility \\
\hline & Cyanotic congenital heart disease \\
\hline & $\begin{array}{l}\text { Long-term exposure to medications: } \\
\text { - chronic glucocorticoid therapy } \\
\text { - depot medroxyprogesterone acetate } \\
\text { - chemotherapeutic drugs } \\
\text { - anticonvulsant drugs } \\
\text { - cyclosporine } \\
\text { - heparin }\end{array}$ \\
\hline
\end{tabular}

health and predispose to fractures are listed in Table 1 $[2,17,18,22]$. Among such patients the initial bone density measurement is recommended only when the result may influence the patient management and the patient may benefit due to the implemented therapy $[1,8,22]$. Ordering DXA, other risk factors such as the family history of fragility fractures, the age of onset, severity of any underlying disorders, malnutrition, immobilisation, and exposure to potentially bone-toxic drugs should be taken into account.

According to current vitamin D supplementation guidelines provided by the Polish Society of Paediatric Endocrinology and Diabetes, in Polish children with deficiency and severe deficiency of vitamin D, DXA is also indicated. If the serum level is $<20 \mathrm{ng} / \mathrm{ml}$ in otherwise healthy patients with some skeletal symptoms (bone deformations, bone pain, history of fragility fractures), it is advisable to perform DXA if available [27].

If there is a need to conduct a follow-up DXA examination (e.g. to monitor the effects of a bone-active therapy, the disease progression, and the associated BMD
$Z$-score decrease), the recommended minimum interval is $6-12$ months $[1,19,20]$. To detect meaningful changes in the bone density, 12 months is often a more appropriate period [8].

\section{DXA REPORT INTERPRETATION}

Usually, the DXA report contains information about the patient, such as: age, gender, race/ethnicity, weight, and height. It may also include a relevant medical history, including previous fractures, indications for the scan, the bone age, and the Tanner stage. The result is given in $\mathrm{g} / \mathrm{cm}^{2}$ - BMC, and Z-score - BMD. A Z-score is a standard deviation (SD) score compared with age-matched and sexmatched controls. A $Z$-score can also provide an estimate of the SD for other variables, such as race/ethnicity and height $[4,18]$. Although the $T$-score may be generated automatically on the DXA report, in patients $<20$ years old it is not recommended and should not be taken into account in paediatric reports. According to the World Health Organisation, the $T$-score is reserved for diagnostic use in postmenopausal women and men aged $\geq 50$ years [28]. Using the $T$-score rather than the $Z$-score in children's DXA reports is the most frequent mistake. The $T$-score is based on the BMD of healthy young adults at the peak bone mass, which can lead to the underestimation of BMD and be a reason for a "low bone mass" or "osteoporosis" misdiagnosis $[6,18,29]$. In one study, $62 \%$ of scans classified as "low bone mass" had an interpretation error due to using the $T$-score, despite the presence of the $Z$-score on the DXA result [29].

A DXA report usually also comprises an interpretation, which is important. If there is no relevant history of fractures and the $Z$-score is lower than -2.0 , the result should not contain the term "osteoporosis" and should then be defined as "low bone mineral density for age". It is an important difference between children and adults and needs to be stressed because many clinicians tend to interpret a child's result referring only to BMD. Likewise, "osteopaenia" should not be used to describe densitometry findings in paediatric subjects $[6,8,19,20]$.

Considering the limitations of the DXA findings, it has to be mentioned that reference data in children and teenagers usually refer to the chronological age and are presented as categorised data. This interpretation may lead to mismanagement, especially when the subject's age is close to the boundary for the groups. There is a Polish study that tried to establish continuous normative data for the bone density, but further research in this area is necessary [30]. Moreover, there are still knowledge gaps that constitute limitations of densitometry in some special groups of patients, such as children with growth retardation or delayed puberty, which is usually connected with delayed skeletal maturation and bone mineral accrual. It is known that short stature confounds the BMD result, because DXA assesses bones in two dimen- 
sions (height and width), while a bone is a three-dimensional object (height, width, and depth). A conventional DXA measurement underestimates the bone density in short people and tends to be higher in taller subjects [1, 31]. Hence, in children with delayed growth or puberty, the BMD should be adjusted to their height or height age, using the height $Z$-score $[4,8,22]$. There is a need to create a normative database for children with delayed puberty or who are small for their age, because using the $Z$-score based on BMD of healthy subjects can lead to misinterpretation [4].

In summary, it is essential to interpret the DXA findings properly. "Osteoporosis" misdiagnosis in every subject can lead to the implementation of an inappropriate treatment, to an extensive diagnostic evaluation to find an underlying disease, and to unnecessary restrictions on physical activity [29].

\section{FRACTURE PREDICTION IN CHILDREN AND ADOLESCENTS}

It is a common belief that fractures mainly affect the elderly, while fracture incidence in childhood is similar to that of the elderly [24]. Almost $50 \%$ of all children will experience a fracture in the first 18 years of life, with an initial peak during puberty (half of all boys and one-third of girls) $[4,13,18]$. One fifth will have two or more fractures. The most common location of fractures in the paediatric population is the forearm. About $30 \%$ of all fractures concern this area [13]. Originally, it was attributed to increased physical activity in this age group. More recent studies, however, suggest that fractures may be caused by changes in the skeletal status and bone geometry during puberty, which possibly result in a transient deterioration in the skeletal strength $[4,9,24]$. Although there are limited data describing the relationship between low BMD and the fracture risk in children and teenagers, Clark et al. (as mentioned above) reported an inverse association between BMD and the fracture risk in childhood [24]. In turn, according to the study by Henderson et al., in children with motor disabilities every $1 \mathrm{SD}$ reduction in the BMD $Z$-score at $\mathrm{LDF}$ was connected with an increased fracture risk at this site [32]. However, these findings need further research, and according to ISCD Paediatric Positions, the BMD Z-score $>-2.0$ does not preclude the possibility of bone fragility and an increased fracture risk [13]. On the other hand, according to the guidelines, in children suffering from some chronic conditions and those who are GC-treated, DXA is recommended to identify the group of patients at high risk of incidental fractures. However, a positive and negative predictive value of low BMD in these patients has not been established [22].

Low BMD is thought to be connected not only with an increased fracture risk. According to the study by Hagner et al., in children suffering from neurofibro- matosis type $1, B M D$ is significantly lower when bone abnormalities (e.g. scoliosis, dysplastic disorders) are present [33].

\section{OTHER METHODS OF BONE MINERAL DENSITY ASSESSMENT}

The paediatric skeleton can also be assessed by using quantitative computed tomography (QCT), peripheral QCT (pQCT), high-resolution pQCT (HR-pQCT), quantitative ultrasonography (QUS), or MRI. Although conventional radiograph remains the gold standard in the diagnosis of fractures, a visual assessment of BMD based on the opacity of radiographs also allows the detection of bone demineralisation ("washed out bones"). Such an evaluation is possible when bone mineralisation is reduced at least by ca. $30 \%$. However, the clinical application of these findings is limited $[23,25]$.

\section{QUANTITATIVE COMPUTED TOMOGRAPHY}

QCT is a three-dimensional technique that allows the assessment of volumetric BMD - BMD in $\mathrm{g} / \mathrm{cm}^{3}$. This measurement is independent of the bone size and assesses the trabecular bone separately from the cortical bone, thus providing information that cannot be obtained with the DXA examination. The measurement is usually performed using a general-purpose CT scanner $[11,33]$. The scan time is fast $(<30 \mathrm{~s})$; however, the radiation exposure is higher than during a DXA scan, but comparable with that of a chest radiograph [10].

\section{PERIPHERAL QUANTITATIVE COMPUTED TOMOGRAPHY}

Peripheral QCT aims to assess appendicular skeletal sites - arms or legs (nondominant radius or tibia), using general-purpose or dedicated peripheral scanners. This method is useful in children with contractures, metal implants, or spinal deformities, where a DXA scan can be difficult to obtain $[2,34]$, and it requires less radiation than QCT [1]. Unfortunately, the cortical BMD cannot be assessed accurately because of thinner cortices in paediatric patients [6].

\section{HIGH-RESOLUTION PERIPHERAL QUANTITATIVE COMPUTED TOMOGRAPHY}

In this technique the trabecular and cortical bone architecture and microarchitectural changes resulting from treatment can be quantified. However, because of its expense, long acquisition time, and limitation to imaging extremities, it is currently used mainly for research purposes [2, 34].

Because of lack of data, there is no recommended method of QCT in children and teenagers. The limitation 
of QCT is paucity of standardised databases, so results cannot be used for fracture prediction or the diagnosis of low bone density $[1,34]$.

\section{QUANTITATIVE ULTRASONOGRAPHY}

QUS is a portable and non-invasive method of bone density assessment that is free of ionising radiation [35, 36]. This examination evaluates the axial transmission speed of sound and the broadband attenuation measured at the calcaneus, mid-tibia, distal radius, or proximal phalanges. QUS provides information both on bone quality (such as elasticity and architecture, which are not revealed by DXA) and bone quantity [35, 37]. Previous studies performed in children and adolescents (e.g. normal population, training karate, children with type 1 diabetes, renal failure, genetic disorders, girls suffering from anorexia nervosa) proved that QUS is an appropriate method for the assessment of skeletal status in young subjects [35-42]. Moreover, the possibility to assess the fracture risk in various metabolic bone diseases with QUS was reported $[36,38]$. There are also opinions that quantitative ultrasound may have the potential to overcome many of the limitations of DXA imaging [40]. However, the limitations of QUS may include inaccuracy and difficulties in obtaining a repeatable result [6].

\section{CONCLUSIONS}

Among the different methods available for bone mineral density measurement in children, dual-energy X-ray absorptiometry remains the method of choice. Adequate interpretation of the DXA examination is crucial to prevent over- and underdiagnosis of bone mineral impairment in children and adolescents.

\section{DISCLOSURE}

The authors declare no conflict of interest.

\section{REFERENCES}

1. Bachrach LK. Diagnosis and treatment of pediatric osteoporosis. Curr Opin Endocrinol Diabetes Obes 2014; 21: 454-460.

2. Saraff V, Högler W. Endocrinology And Adolescence. Osteoporosis in children: diagnosis and management. Eur J Endocrinol 2015; 173: R185-197.

3. Di Iorgi N, Maruca K, Patti G, et al. Update on bone density measurements and their interpretation in children and adolescents. Best Pract Res Clin Endocrinol Metab 2018; 32: 477-498.

4. Crabtree NJ, Arabi A, Bachrach LK, et al.; International Society for Clinical Densitometry. Dual-energy X-ray absorptiometry interpretation and reporting in children and adolescents: the revised 2013 ISCD Pediatric Official Positions. J Clin Densitom 2014; 17: 225-242.

5. Jakubowska-Pietkiewicz E, Ligenza I, Łupińska A, et al. Zależność pomiędzy wymiarami ciała u dzieci a masą kostną. Pediatr Pol 2008; 83: 363-367.
6. Messina C, Lastella G, Sorce S, et al. Pediatric dual-energy X-ray absorptiometry in clinical practice: What the clinicians need to know. Eur J Radiol 2018; 105: 153-161.

7. Sioen I, Lust E, De Henauw S, et al. Associations Between Body Composition and Bone Health in Children and Adolescents: A Systematic Review. Calcif Tissue Int 2016; 99: 557-577.

8. Bachrach LK, Gordon CM, AAP Section On Endocrinology. Bone Densitometry in Children and Adolescents. Pediatrics 2016; 138: e20162398.

9. Wren TA, Shepherd JA, Kalkwarf HJ, et al. Racial disparity in fracture risk between white and nonwhite children in the United States. J Pediatr 2012; 161: 1035-1040.

10. Wasilewski-Masker K, Kaste SC, Hudson MM, et al. Bone mineral density deficits in survivors of childhood cancer: long-term follow-up guidelines and review of the literature. Pediatrics 2008; 121: e705-713.

11. Kim HY, Jung HW, Hong H, et al. The Role of Overweight and Obesity on Bone Health in Korean Adolescents with a Focus on Lean and Fat Mass. J Korean Med Sci 2017; 32: 1633-1641.

12. Łupińska A, Chlebna-Sokół D. Wybrane czynniki wpływające na masę kostną uczniów łódzkich szkół w wieku 7-10 lat z rozpoznaną otyłością. Pediatr Med Rodz 2017; 13: 514-526.

13. Bishop N, Arundel P, Clark E, et al. International Society of Clinical Densitometry. Fracture prediction and the definition of osteoporosis in children and adolescents: the ISCD 2013 Pediatric Official Positions. J Clin Densitom 2014; 17: 275-280.

14. Tan VP, Macdonald HM, Kim S, et al. Influence of physical activity on bone strength in children and adolescents: a systematic review and narrative synthesis. J Bone Miner Res 2014; 29: 2161-2181.

15. Julián-Almárcegui C, Gómez-Cabello A, Huybrechts I, et al. Combined effects of interaction between physical activity and nutrition on bone health in children and adolescents: a systematic review. Nutr Rev 2015; 73: 127-139.

16. Siminoski K, Lee KC, Jen $\mathrm{H}$, et al. Anatomical distribution of vertebral fractures: comparison of pediatric and adult spines. Osteoporos Int 2012; 23: 1999-2008.

17. Ward LM, Konji VN, Ma J. The management of osteoporosis in children. Osteoporos Int 2016; 27: 2147-2179.

18. Estrada A, Ramnitz MS, Gafni RI. Bone densitometry in children and adolescents. Curr Opin Obstet Gynecol 2014; 26: 339-346.

19. Gordon CM, Leonard MB, Zemel BS. 2013 Pediatric Position Development Conference: Executive Summary and Reflections. J Clin Densitom 2014; 17: 219-224.

20. Wasserman H, O'Donnell JM, Gordon CM. Use of dual energy X-ray absorptiometry in pediatric patients. Bone 2017; 104: 84-90.

21. Zemel BS, Stallings VA, Leonard MB, et al. 2009 Revised pediatric reference data for the lateral distal femur measured by Hologic Discovery/Delphi dual-energy X-ray absorptiometry. J Clin Densitom 2009; 12: 207-218.

22. Bianchi ML, Leonard MB, Bechtold S, et al. Bone health in children and adolescents with chronic diseases that may affect the skeleton: the 2013 ISCD Pediatric Official Positions. J Clin Densitom 2014; 17: 281-294.

23. Chlebna-Sokół D, Woźniak E, Jakubowska-Pietkiewicz E. Current rules for the diagnosis and treatment of bone metabolic diseases in children and adolescents. Pediatr Endocrinol 2018; 17: 47-58.

24. Clark EM, Ness AR, Bishop NJ, et al. Association between bone mass and fractures in children: a prospective cohort study. J Bone Miner Res 2006; 21: 1489-1495.

25. Kalkwarf HJ, Abrams SA, DiMeglio LA, et al; Bone densitometry in infants and young children: the 2013 ISCD Pediatric Official Positions. J Clin Densitom 2014; 17: 243-257. 
26. Aris RM, Merkel PA, Bachrach LK, et al. Guide to bone health and disease in cystic fibrosis. J Clin Endocrinol Metab 2005; 90: 18881896.

27. Rusińska A, Płudowski P, Walczak M, et al. Vitamin D Supplementation Guidelines for General Population and Groups at Risk of Vitamin D Deficiency in Poland-Recommendations of the Polish Society of Pediatric Endocrinology and Diabetes and the Expert Panel With Participation of National Specialist Consultants and Representatives of Scientific Societies-2018 Update. Front Endocrinol (Lausanne) 2018; 31: 246.

28. Kanis JA on behalf of the World Health Organization Scientific Group (2007). Assessment of osteoporosis at the primary healthcare level. Technical Report. World Health Organization Collaborating Centre for Metabolic Bone Diseases, University of Sheffield, UK 2007.

29. Gafni RI, Baron J. Overdiagnosis of osteoporosis in children due to misinterpretation of dual-energy $\mathrm{x}$-ray absorptiometry (DEXA). J Pediatr 2004; 144: 253-257.

30. Jaworski M, Płudowski P. Specific interpretation of bone mineral density and body composition measurements in children and adolescents - categorized and continuous normative data for mechanostat. Stand Med Pediatr 2009; 6: 292-303.

31. Crabtree NJ, Högler W, Cooper MS, et al. Diagnostic evaluation of bone densitometric size adjustment techniques in children with and without low trauma fractures. Osteoporos Int 2013; 24: 2015-2024.

32. Henderson RC, Berglund LM, May R, et al. The relationship between fractures and DXA measures of BMD in the distal femur of children and adolescents with cerebral palsy or muscular dystrophy. J Bone Miner Res 2010; 25: 520-526.

33. Hagner A, Marjańska A, Dziedzic M, et al. Evaluation of bone abnormalities in children with neurofibromatosis type 1. Pediatr Pol 2018; 92: 675-680.

34. Adams JE, Engelke K, Zemel BS, et al. Quantitative computer tomography in children and adolescents: the 2013 ISCD Pediatric Official Positions. J Clin Densitom 2014; 17: 258-274.

35. Adamczyk P, Pluskiewicz W. Karate Training Improves Skeletal Status Assessed by Quantitative Ultrasound in Girls and Premenopausal Women. J Clin Densitom 2018 Jul; doi: 10.1016/j. jocd.2018.07.008 (in press).

36. Drozdzowska B, Pluskiewicz W, Halaba Z, et al. Quantitative ultrasound at the hand phalanges in 2850 females aged 7 to $77 \mathrm{yr}$ : a cross-sectional study. J Clin Densitom 2005; 8: 216-221.

37. Oświecimska J, Ziora K, Pluskiewicz W, et al. Skeletal status and laboratory investigations in adolescent girls with anorexia nervosa. Bone 2007; 41: 103-110.

38. Bolanowski M, Pluskiewicz W, Syrycka J, et al. Quantitative Ultrasound at the Hand Phalanges in Adolescent Girls is Related to Their Overall Physical Fitness. Adv Clin Exp Med 2016; 25: 279-284.

39. Chwałczyńska A, Pluskiewicz W, Syrycka J, et al. Quantitative ultrasound at the hand phalanges in adolescent boys in relation to their pubertal development and physical efficiency. Endokrynol Pol 2013; 64: 353-357.

40. Chobot AP, Haffke A, Polanska J, et al. Quantitative ultrasound bone measurements in pre-pubertal children with type 1 diabetes. Ultrasound Med Biol 2012; 38: 1109-1115.

41. Pluskiewicz W, Adamczyk P, Drozdzowska B, et al. Skeletal status in adolescents with end-stage renal failure: a longitudinal study. Osteoporos Int 2005; 16: 289-295.

42. Pluskiewicz W, Adamczyk P, Drozdzowska B, et al. Quantitative ultrasound and peripheral bone densitometry in patients with genetic disorders. Ultrasound Med Biol 2006; 32: 523-528. 